\title{
BMI was found to be a consistent determinant related to misreporting of energy, protein and potassium intake using self-report and duplicate portion methods
}

\author{
Laura Trijsburg ${ }^{1}$, Anouk Geelen ${ }^{1}$, Peter CH Hollman ${ }^{1}$, Paul JM Hulshof ${ }^{1}$, Edith JM Feskens ${ }^{1}$, \\ Pieter van't Veer ${ }^{1}$, Hendriek C Boshuizen ${ }^{1,2}$ and Jeanne HM de Vries ${ }^{1, *}$ \\ 'Division of Human Nutrition, Wageningen University, PO Box 8129, 6700 EV Wageningen, The Netherlands: \\ ${ }^{2}$ Biometris, Wageningen University, Wageningen, The Netherlands
}

Submitted 5 April 2016: Final revision received 26 August 2016: Accepted 2 September 2016: First published online 110 0ctober 2016

\begin{abstract}
Objective: As misreporting, mostly under-reporting, of dietary intake is a generally known problem in nutritional research, we aimed to analyse the association between selected determinants and the extent of misreporting by the duplicate portion method (DP), $24 \mathrm{~h}$ recall (24hR) and FFQ by linear regression analysis using the biomarker values as unbiased estimates.

Design: For each individual, two DP, two $24 \mathrm{hR}$, two FFQ and two $24 \mathrm{~h}$ urinary biomarkers were collected within 1.5 years. Also, for sixty-nine individuals one or two doubly labelled water measurements were obtained. The associations of basic determinants (BMI, gender, age and level of education) with misreporting of energy, protein and $\mathrm{K}$ intake of the DP, 24hR and FFQ were evaluated using linear regression analysis. Additionally, associations between other determinants, such as physical activity and smoking habits, and misreporting were investigated.

Setting: The Netherlands.

Subjects: One hundred and ninety-seven individuals aged 20-70 years.

Results: Higher BMI was associated with under-reporting of dietary intake assessed by the different dietary assessment methods for energy, protein and $\mathrm{K}$, except for $\mathrm{K}$ by DP. Men tended to under-report protein by the DP, FFQ and 24hR, and persons of older age under-reported $\mathrm{K}$ but only by the $24 \mathrm{hR}$ and FFQ. When adjusted for the basic determinants, the other determinants did not show a consistent association with misreporting of energy or nutrients and by the different dietary assessment methods.

Conclusions: As BMI was the only consistent determinant of misreporting, we conclude that BMI should always be taken into account when assessing and correcting dietary intake.
\end{abstract}

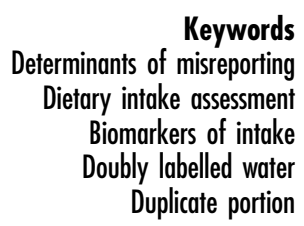

\begin{abstract}
Misreporting, mostly under-reporting, of dietary intake is a generally known problem in nutritional research and has been shown to affect estimates based on diet assessment methods, including FFQ, $24 \mathrm{~h}$ recalls ( $24 \mathrm{hR})$, food records and the duplicate portion method (DP $)^{(1-5)}$. Identifying the determinants associated with misreporting of dietary intake may help to facilitate the adjustment of dietary assessment methods and the development of correction methods. A large body of evidence has demonstrated that various determinants, such as a higher BMI, gender, being of older age and smoking, are associated with underreporting of energy intake. The identified determinants depended on the research question and type of analysis, the population studied and the availability of different sets of determinants in the studies ${ }^{(6,7)}$.
\end{abstract}

To assess the degree of misreporting of energy intake, energy expenditure measured by the doubly labelled water method (DLW), a recovery biomarker, is the preferred reference method ${ }^{(8)}$. The method assumes that participants are in energy balance. Other recovery biomarkers are available for a limited number of nutrients, including protein, $\mathrm{K}$ and $\mathrm{Na}^{(8,9)}$. However, relatively few studies have addressed the associations of determinants with misreporting of these nutrients ${ }^{(2,10-13)}$. Having a high BMI was consistently associated with under-reporting of energy and nutrients for different dietary assessment methods $^{(10,11,14-17)}$. Results for gender did not always point in the same direction: under-reporting of energy intake was found to be more prevalent in women than men for $24 \mathrm{hR}^{(14,18)}$, and under-reporting of energy 
assessed by FFQ was higher in men ${ }^{(19)}$. Having a lower level of education ${ }^{(16,19)}$ and being older ${ }^{(14,19)}$ were also associated with under-reporting of energy intake for both FFQ and 24hR. Other determinants reported to be associated with energy misreporting by $24 \mathrm{hR}$ include, but are not limited to, body fatness ${ }^{(18,20)}$, smoking status and physical activity level ${ }^{(14)}$. Although studies investigating misreporting include different sets of determinants, usually BMI, gender, age and level of education (or another indicator of socio-economic status) are included; we refer to these determinants as the 'basic determinants'. To our knowledge, determinants associated with misreporting have not been studied for the DP method before.

We aimed to assess the associations of the basic determinants (BMI, gender, age and education level) with misreporting of energy, protein and $\mathrm{K}$ for three dietary assessment methods: FFQ, 24hR and DP. Our secondary aim was to additionally assess the associations of a number of selected determinants with misreporting of the same nutrients for these dietary assessment methods. We included a set of explorative determinants including BMI-related determinants, as BMI is strongly associated with misreporting, and other personal characteristics (Table 1). The recovery biomarkers for energy, protein and $\mathrm{K}$ were used to assess the degree of misreporting.

\section{Materials and methods}

\section{Participants and design}

The recruitment and procedures of the DuPLO study, which was conducted between July 2011 and July 2014, are described elsewhere ${ }^{(21)}$. Briefly, a sub-sample of 200 Dutch adults (ninety-two men, 108 women) from the NQPlus study, aged 20-70 years and living in the surroundings of
Wageningen, the Netherlands, were recruited. Baseline measurements consisted of, among others, a physical examination including weight and height, general questionnaires (including questions about education, health and smoking habits), and lifestyle and psychosocial questionnaires. For the data analyses in the DuPLO study, we used data from the NQPlus study, and collected additional data in the same participants. Data of the NQplus study were collected within a time frame of 1 year and consisted of two self-reports by FFQ ( $\sim$ months apart), two urine samples ( 1 year apart) and the first two collected telephone-based $24 \mathrm{hR} \quad(\sim 7$ months apart). For the DuPLO study, which started after the NQPlus study, two DP ( $\sim 5$ months apart) were collected from each participant and energy expenditure was assessed by the DLW method, once for seventy participants (thirty-seven men, thirty-three women) and twice for thirty participants. Eventually all measurements were collected within a time frame of 1.5 years.

\section{Dietary intake assessment}

An extended description of the dietary intake assessment is presented elsewhere ${ }^{(21)}$. In short, the $24 \mathrm{hR}$ was administered by trained dietitians following a standard protocol based on the five-step multiple-pass method ${ }^{(22)}$. The 180-item $\mathrm{FFQ}^{(23,24)}$ was self-administered using the open-source online survey tool Limesurvey ${ }^{\mathrm{TM}}$ (LimeSurvey Project Team/Carsten Schmitz, Hamburg, Germany, 2012). The Dutch food composition database of $2011^{(25)}$ was used to calculate energy, protein and $\mathrm{K}$ intakes from the $24 \mathrm{hR}$ and FFQ.

For the DP all foods and drinks consumed over a $24 \mathrm{~h}$ time period were collected by the participants and weighed, homogenized and stored until further analysis by

Table 1 Classification of the determinants related to misreporting of energy, protein and potassium intake used in the present study

\begin{tabular}{lll}
\hline Classification & Determinant & Method used to assess \\
\hline Basic determinants & Age (years) & General questionnaire \\
& BMl (kg/m²) & Physical measurements \\
& Gender & General questionnaire \\
EDU (high-intermediate-low) & General questionnaire \\
& Opinion BW: too high (yes-no) & General questionnaire \\
& Dieting: sometimes (yes-no) & General questionnaire \\
& Total number of dieting attempts & General questionnaire \\
& Maximal 5-year weight difference (kg) & General questionnaire \\
& Physical activity (MET/d) & Accelerometer \\
& Body fat (\%) & DXA scan or Tanita body composition analyser \\
& Stress level (score 1-5) & Perceived Stress Scale (PSS4) \\
& Restrained eater (score 1-5) & Dutch Eating Behaviour Questionnaire \\
& Emotional eater (score 1-5) & Dutch Eating Behaviour Questionnaire \\
& External eater (score 1-5) & Dutch Eating Behaviour Questionnaire \\
& Knowledge about healthy eating (score 0-17) & Nutrition Behaviour Questionnaire \\
& Self-identity with healthy eating (score 1-7) & Nutrition Behaviour Questionnaire \\
& Perceived barriers for healthy eating (score 1-7) & Nutrition Behaviour Questionnaire \\
& Smoking (never-yes-former) & General questionnaire \\
& Living with partner (yes-no) & General questionnaire
\end{tabular}


the researcher. On the day of the $24 \mathrm{~h}$ urine collections, participants were instructed to ingest three $80 \mathrm{mg}$ tablets of $p$-aminobenzoic acid (PABA) to check for urine completeness. At the research centre urines were mixed, weighed and aliquoted, and stored at $-20^{\circ} \mathrm{C}$ until further analyses.

\section{Laboratory measures}

$\mathrm{N}$ was assessed with the Kjeldahl technique ${ }^{(26)}$ in both DP and urine. The amount of protein was calculated using an $\mathrm{N}$ to protein conversion factor of $6 \cdot 25^{(27)}$ and an average ratio of urinary $\mathrm{N}$ excretion to dietary $\mathrm{N}$ of $0 \cdot 81^{(28)}$ was assumed. $\mathrm{K}$ in urine was determined with an ion-selective electrode and intake was calculated taking into account extra-renal and faecal losses of $19 \%^{(10)}$. PABA in urine was assessed by the HPLC method; based on the cut-off value of $78 \%$ PABA recovery ${ }^{(29)}, 70 \%$ of the urines were considered complete. Incomplete urines were not excluded from the analysis, but the measure for PABA completeness (complete $=0$ and incomplete $=1$ ) was included as a covariate in the linear regression model. $\mathrm{K}$ in the DP was determined, after digestion of the samples in polytetrafluoroethylene tubes using a MarsXpress microwave digestor (CEM, Matthews, NC, USA), by inductively coupled plasma-atomic emission spectroscopy (Varian Australia Pty Ltd, Mulgrave, Australia). The fat content of the DP was assessed by the acid hydrolysis method $^{(30)}$, ash by heating the freeze-dried food in a muffle furnace at $550{ }^{\circ} \mathrm{C}^{(31)}$, alcohol by $\mathrm{GC}^{(32)}$ and the moisture content was assessed by drying in a vacuum oven ${ }^{(31)}$. We assumed water, ash, fat, protein, alcohol and total carbohydrates (including dietary fibre) summed up to $100 \%$ of the total weight of the $\mathrm{DP}^{(33)}$. Total carbohydrates were calculated by difference ${ }^{(34)}$. Energy content of the DP was subsequently calculated from the total amount of protein, fat, total carbohydrates (including dietary fibre) and alcohol using the general Atwater factors for these nutrients: 17, 37 , 17 and $29 \mathrm{~kJ} / \mathrm{g}$, respectively.

Total energy expenditure for each participant, covering an $11 \mathrm{~d}$ period, was assessed by the DLW method using the two-point protocol $^{(35)}$. Total energy expenditure was calculated using the modified Weir equation ${ }^{(36)}$ where the respiratory quotient was assumed to be 0.85. A detailed description of the DLW protocol can be found elsewhere ${ }^{(37)}$.

\section{Determinants}

\section{Physical measurements}

Physical measurements were done at baseline by trained research assistants following a standardized protocol. Height was measured to the nearest $0 \cdot 1 \mathrm{~cm}$ without shoes with a stadiometer (Seca, Hamburg, Germany). Weight was measured with empty pockets and without shoes and sweaters to the nearest $0 \cdot 1 \mathrm{~kg}$ on a digital scale (Seca). BMI was calculated by dividing weight (in kilograms) by the square of the body height (in metres). Body fat percentage was measured by dual-energy X-ray absorptiometry scan (Lunar Prodigy; GE Healthcare, Madison, WI, USA). Quality assurance measurements for dual-energy X-ray absorptiometry were performed daily to ensure scanner reliability. In the case that the participant's body did not fit the outline of the scanner $(n 1)$, the scan results of the right side of the body were used to estimate body composition of the body's left side. In a sub-sample ( $n$ 27), body fat percentage was measured using a body composition analyser (model BC418MA; Tanita Corporation) instead.

\section{General questionnaire}

Participants were contacted by email and asked to complete questionnaires online using the open-source survey tool Limesurvey ${ }^{\mathrm{TM}}$. The general questionnaire administered at baseline included questions about age, gender, household composition, current and previous smoking habits, dieting habits, opinion about body weight, highest and lowest weight in the past 5 years and education level. Never smokers were those who had not smoked in the past month and never smoked for a full year. Participants who smoked in the past month or ever smoked for a full year and did not stop smoking were classified as current smokers. Participants who ever smoked for a full year, but had not smoked in the past month and stopped smoking were classified as former smokers. Participants with no education or primary or lower vocational education as highest completed education were classified as having a low education level. Participants who completed lower secondary or intermediate vocational education were classified as having an intermediate education level and participants with a high education level were those who completed higher secondary education, higher vocational education or university.

\section{Physical activity}

Physical activity was assessed by accelerometer, the triaxial GT3X or triaxial GT3X + (ActiGraph, Pensacola, FL, USA), and expressed in metabolic equivalents of task (MET) per day. Participants wore the accelerometer for seven continuous days on their hip and kept a record of daily activities. ActiLife software version 6.7.3 (ActiGraph) was used to assess daily MET scores with the equation developed by Swartz et al. ${ }^{(38)}$.

\section{Perceived Stress Scale}

The Perceived Stress Scale (PSS) measures the degree to which situations are considered stressful. The PSS asks about feelings and thoughts in the last two weeks ${ }^{(39)}$. Within the present study, the four-item version of the PSS (i.e. the PSS4) was used. A total PSS4 score was derived by reversing the scores of the two positively stated items and then summing across all four items (range 0 to 16). The internal consistency of the PSS4 has been found acceptable $(\alpha=0.72)$ and the test-retest reliability was fair $(0.55)^{(39)}$. 


\section{Dutch Eating Behaviour Questionnaire}

The Dutch Eating Behaviour Questionnaire (DEBQ) ranks participants on a scale of 1 to 5 on three eating styles: (i) restrained eating, i.e. conscious restriction of food intake; (ii) emotional eating, i.e. eating resulting from negative moods; and (iii) external eating, i.e. eating as a response to the smell or sight of food ${ }^{(40)}$. The questionnaire comprises thirty-three statements to be rated on a 5-point scale. The mean of the total score for each eating style was taken and used for the analysis. The DEBQ was found to successfully identify the three dimensions of eating style in clinical and non-clinical groups ${ }^{(41)}$.

\section{Nutrition Behaviour Questionnaire}

Based on the theory of planned behaviour and the transtheoretical model, a questionnaire was developed to assess self-identity, knowledge and perceived barriers for healthy eating in general as previously described ${ }^{(42)}$. In short, for self-identity the mean score of three statements about one's identification to be a healthy eater, with answering scales ranging from 1 to 7 , was used. Knowledge was assessed by two types of questions, the first set consisted of statements about the Dutch dietary guidelines for a healthy diet of 2006 and the second set asked participants to select the healthier choice from pairs of foods. For each correct answer the participants received 1 point and the sum score ranged from 0 to 17 points. Perceived barriers were assessed by thirteen statements related to barriers for healthy eating on a 7-point scale. Mean scores ranging from 1 to 7 were used in the current analysis.

\section{Statistical analysis}

In total, 197 out of the 200 participants were included for analysis of protein and $\mathrm{K}$ misreporting, ninety-one men and 106 women. Two participants became pregnant during the study. As it was expected that they changed their habitual dietary intake, they were excluded from analysis. One participant did not collect urine samples and was therefore also excluded from analysis. Furthermore, DLW energy expenditure data of one participant were excluded because of physiologically implausible body water changes between repeated measurements while body weight remained stable. Thus, data of thirty-seven men and thirty-two women were included in the analysis of energy misreporting. Data were approximately normally distributed on the original scale. Participants with missing data for one or more of the methods were included in the analysis because they provided information for the other dietary assessment methods. In the tables $N$ represents the number of participants included in the analysis for the specific dietary assessment method. Multiple imputations were used to impute missing determinant data. Ten sets of imputed data were generated and the results from the ten analyses were combined using the standard pooling rules. The highest percentage of missing data was $15.2 \%$ for the variable 5-year weight difference.

Misreporting on the group level was calculated as the intake assessed by a single measurement of DP, $24 \mathrm{hR}$ or FFQ minus the mean of two measurements of the recovery biomarkers for protein, K or energy (where for DLW, for forty participants, only one measurement was available). This was done for both measurements of DP, $24 \mathrm{hR}$ and FFQ separately. Following this the mean of the two biases was reported for DP, $24 \mathrm{hR}$ and FFQ. The percentage bias was calculated by taking the mean of the bias percentages at the individual level. A Student's paired $t$ test between the mean of the recovery biomarkers and the mean of the two intakes based on FFQ, DP or $24 \mathrm{hR}$ was performed to test for statistical significance of misreporting. Descriptive statistics are presented as percentages and as means with their standard deviations.

Linear regression analysis was performed to relate the basic determinants (BMI, gender, age and education level) and an intercept, all in one model, to the bias; that is, the difference between reported intake by DP, $24 \mathrm{hR}$ or FFQ and estimated intake based on the biomarker for energy, protein and $\mathrm{K}$ intake. For education two dummies were included in the model. Recovery of PABA (complete yes or no) was included in all models for protein and $\mathrm{K}$ as a methodological factor related to the urine collection. Next, the explorative determinants were added to this multiple linear regression model, one at a time. For smoking, two dummies indicating formerly or currently smoking were simultaneously included in the model. To test for interaction between gender and body fat, the model including the basic determinants and the interaction term for gender and body fat was run. All statistical tests were performed using the statistical software package SAS version 9.3.

\section{Results}

\section{Baseline characteristics of the study population}

The participants had a mean age of $55 \cdot 8$ (SD 10.1) years and a mean BMI of $25 \cdot 1$ (SD 3.7) $\mathrm{kg} / \mathrm{m}^{2}$ (Table 2). Slightly more women were enrolled (53.8\%) than men and $52.8 \%$ of the participants completed a high level of education while $18.8 \%$ had a low level of education.

Baseline values of the explorative BMI-related determinants showed that $54.3 \%$ of the participants judged their body weight as too high. Almost one-third (31.8\%) of the participants had followed a weight-loss diet, and reported on average four attempts to follow such a diet. Furthermore, the self-reported maximum weight difference within the previous 5 -year period was $7.6 \mathrm{~kg}$. The mean physical activity level was 1.78 (SD 0.19) MET/d and participants had on average $28 \%$ body fat. Mean PSS 4 scores and the scores on the DEBQ (restrained, emotional or external eater) were fairly average (about 2.5), and participants on average answered fifteen out of seventeen questions correctly 
Table 2 Baseline characteristics of the study participants $(n$ 197) aged 20-70 years from Wageningen, the Netherlands

\begin{tabular}{|c|c|c|}
\hline & Mean & SD \\
\hline Age (years) & $55 \cdot 8$ & $10 \cdot 1$ \\
\hline BMI $\left(\mathrm{kg} / \mathrm{m}^{2}\right)$ & $25 \cdot 1$ & 3.7 \\
\hline Total dieting attempts & 4 & 10 \\
\hline 5-year weight difference $(\mathrm{kg})$ & 7.57 & $6 \cdot 31$ \\
\hline Physical activity (MET/d) & 1.78 & 0.19 \\
\hline Body fat (\%) & $28 \cdot 3$ & $9 \cdot 26$ \\
\hline Stress level $(1-5) \dagger$ & 2.55 & 2.90 \\
\hline Restrained eater $(1-5) \ddagger$ & 2.97 & 0.69 \\
\hline Emotional eater $(1-5) \ddagger$ & 2.03 & 0.70 \\
\hline External eater $(1-5) \ddagger$ & 2.49 & 0.50 \\
\hline Knowledge $(0-17) \S$ & 14.7 & 1.8 \\
\hline Self-identity (1-7)\| & 5.51 & 0.87 \\
\hline \multirow[t]{2}{*}{ Perceived barriers (1-7) } & $2 \cdot 28$ & 0.79 \\
\hline & $\%$ & \\
\hline Gender: men & $46 \cdot 2$ & \\
\hline Gender: women & 53.8 & \\
\hline EDU: low & $18 \cdot 8$ & \\
\hline EDU: intermediate & $28 \cdot 4$ & \\
\hline EDU: high & 52.8 & \\
\hline Opinion BW: too high & $54 \cdot 3$ & \\
\hline Dieting: sometimes & $31 \cdot 8$ & \\
\hline Smoking: never & $40 \cdot 8$ & \\
\hline Smoking: current & 7.8 & \\
\hline Smoking: former & 51.4 & \\
\hline Living with partner & $80 \cdot 2$ & \\
\hline Living with children & $21 \cdot 8$ & \\
\hline
\end{tabular}

MET, metabolic equivalents of task; EDU, education level; BW, body weight. †A higher stress score means the perceived stress is higher.

$\ddagger A$ higher score on restrained, emotional or external eating means the eating behaviour of the person is leaning more to the specific eating pattern.

$\S \mathrm{A}$ higher score on knowledge means the person has a higher knowledge about healthy eating.

$\| A$ higher score on self-identity means the person identifies him-/herself with eating healthily.

IA higher score on perceived barriers means the perceived barriers for eating healthily are higher.

regarding knowledge about healthy eating. Furthermore, $7.8 \%$ of participants were currently smoking. Most participants were living with a partner (80.2\%) and $21.2 \%$ lived with children.

\section{Misreporting of energy, protein and potassium intake}

All dietary assessment methods statistically significantly underestimated the intake of energy, protein and $\mathrm{K}$ based on comparison with the biomarker (Table 3). Energy and protein were underestimated by approximately $20 \%$, except for protein assessed by the $24 \mathrm{hR}$, which was underestimated by $12 \%$ (averages of individual biases as percentage). $\mathrm{K}$ intake was underestimated to a smaller extent: 6.8, 3.9 and $8 \cdot 2 \%$ by DP, $24 \mathrm{hR}$ and FFQ, respectively.

\section{Basic determinants associated with misreporting}

A higher BMI was associated with under-reporting of energy and protein to a similar degree for all methods. An increase in BMI of $1 \mathrm{~kg} / \mathrm{m}^{2}$ led to an increase in under-reporting of energy by $279 \mathrm{~kJ}$ for the DP, $204 \mathrm{~kJ}$ for the $24 \mathrm{hR}$ and $272 \mathrm{~kJ}$

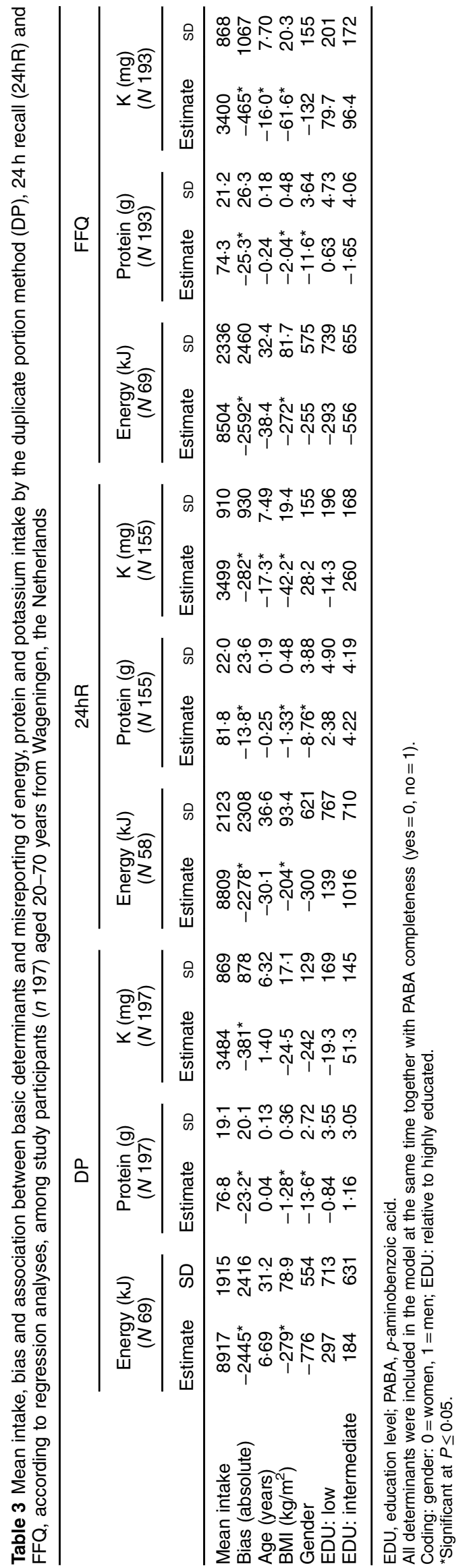


for the FFQ, and of protein by $1.3,1.3$ and $2.0 \mathrm{~g}$ for the respective dietary assessment methods (Table 3 ). BMI was associated with under-reporting of $\mathrm{K}$ assessed by the memory-based methods $24 \mathrm{hR}$ and FFQ, but not by DP. Being of older age was associated with misreporting of $\mathrm{K}$ intake, also only by $24 \mathrm{hR}$ and FFQ. For a 1 -year increase in age, $\mathrm{K}$ was under-reported by an additional $17 \mathrm{mg}$ by the $24 \mathrm{hR}$ and $16 \mathrm{mg}$ by the FFQ (Table 3). Men showed higher under-reporting than women for protein assessed by all three dietary assessment methods but not for energy. No significant association was observed between misreporting and level of education.

\section{Explorative determinants associated with misreporting}

In addition to the basic determinants mentioned before, further potential determinants were explored one at a time, while accounting for PABA recovery. Only a few significant associations were observed. Participants who were of the opinion that they were too heavy over-reported protein assessed by the FFQ by $9.8 \mathrm{~g}$ on average as compared with those who were of the opinion they had an appropriate body weight (Table 4). Also, a higher percentage of body fat was associated with protein and $\mathrm{K}$ over-reporting in the FFQ ( $0.91 \mathrm{~g}$ and $43 \mathrm{mg}$, respectively). In contrast, a $1 \mathrm{~kg}$ larger weight difference within the past 5 years was associated with protein under-reporting of $0.52 \mathrm{~g}$ but only when assessed by the DP and not by one of the memory-based methods. Also a $1 \mathrm{MET} / \mathrm{d}$ higher physical activity level was associated with a higher level of under-reporting of energy assessed by the $24 \mathrm{hR}$ and FFQ (3916 and $3799 \mathrm{~kJ}$, respectively) but this was not the case for the DP. For protein, $1 \mathrm{MET} / \mathrm{d}$ higher physical activity level was associated with a higher level of underreporting $(22.7 \mathrm{~g})$ for only the $24 \mathrm{hR}$.

Further exploration of the other determinants indicated a higher perception of barriers to eat healthily to be associated with over-reporting of energy assessed by the $24 \mathrm{hR}(984 \mathrm{~kJ})$. For those living in a household with children, more energy under-reporting by the DP $(1495 \mathrm{~kJ})$ was observed compared with those living without children. Also, being a current smoker was associated with under-reporting for protein $(16.7 \mathrm{~g}$ as compared with never smokers) and $\mathrm{K}$ (600 mg) intake as assessed by the FFQ.

\section{Discussion}

We studied the association of determinants with misreporting of three nutrients for DP, $24 \mathrm{hR}$ and FFQ, using biomarkers as the reference method. To our knowledge, the present study is the first to include the DP method in such a validation study. As expected, the study showed that BMI is an important determinant associated with misreporting of energy, protein and $\mathrm{K}$ intake for the different dietary assessment methods. However, we did not see this association for $\mathrm{K}$ assessed by DP. Persons of older age under-reported $\mathrm{K}$ to a larger extent by the $24 \mathrm{hR}$ and FFQ, and men tended to under-report protein to a larger extent than women on the DP, $24 \mathrm{hR}$ and FFQ. Adding the explorative determinants, BMI-related and other, to the basic model did not show associations with misreporting for most of the determinants. For those explorative determinants that did show a significant association with misreporting, no consistent pattern over the three nutrients or dietary assessment methods was observed.

Our finding that a higher BMI is associated with underreporting is consistent with those of other studies ${ }^{(10,14-17)}$. The association between misreporting and a higher BMI might be explained by the selective under-reporting of certain foods (such as unhealthy snacks) by people with a higher $\mathrm{BMI}^{(43)}$. Selective under-reporting of foods may result in differential reporting of nutrients. Selective misreporting of nutrients was proposed by Subar et al. ${ }^{(44)}$ who observed larger under-reporting of energy than of protein, suggesting a bias towards more under-reporting of fat, carbohydrates or alcohol. We also observed this when dietary intake was assessed by $24 \mathrm{hR}$, although not when assessed by DP or FFQ. Social desirability has also been suggested to underlie the under-reporting of people with a higher BMI; however, Taren et $a l .{ }^{(45)}$ demonstrated that social desirability and BMI influence misreporting independently. In our study no variables about number of meals and snacks were included as this is not distinguishable for the DP. For macronutrients such as carbohydrates and fats no recovery biomarkers are presently known ${ }^{(8)}$, so the degree of misreporting for such nutrients can only be estimated using imperfect reference methods. Furthermore, no data on social desirability were available.

The other basic determinants that showed an association with misreporting were gender and age. Men showed higher under-reporting than women for protein on the DP, $24 \mathrm{hR}$ and FFQ. In our study, standard portion sizes were used for the $24 \mathrm{hR}$ and $\mathrm{FFQ}^{(46)}$; as men tend to eat more than women, this might have caused more underestimation of intake for men. For example, the major source of protein intake for men is meat $(29 \%)^{(47)}$, thus if the meat consumption of men is underestimated this will lead to an underestimation of protein intake. However, this does not explain why men also underestimated protein intake by the DP. Older age was significantly associated with higher under-reporting of $\mathrm{K}$ intake, but only for FFQ and $24 \mathrm{hR}$. FFQ and $24 \mathrm{hR}$ are recall methods relying on the memory of the participant while this is not the case for the DP. However, in our population there was little variation in age, thus drawing firm conclusions based on these findings cannot be done.

When looking at the statistically significant explorative BMI-related determinants, our findings are consistent with those of Briefel et al. who also reported an association between the extent of misreporting of energy intake and a higher physical activity level ${ }^{(14)}$. Associations with 
Table 4 Association between explorative determinants and misreporting of energy, protein and potassium intake by the duplicate portion method (DP), $24 \mathrm{~h}$ recall (24hR) and FFQ, according to regression analyses, among study participants ( $n$ 197) aged $20-70$ years from Wageningen, the Netherlands

\begin{tabular}{|c|c|c|c|c|c|c|c|c|c|c|c|c|c|c|c|c|c|c|}
\hline & \multicolumn{6}{|c|}{ DP } & \multicolumn{6}{|c|}{$24 \mathrm{hR}$} & \multicolumn{6}{|c|}{ FFQ } \\
\hline & \multicolumn{2}{|c|}{$\begin{array}{l}\text { Energy (kJ) } \\
\quad(N 69)\end{array}$} & \multicolumn{2}{|c|}{$\begin{array}{l}\text { Protein }(\mathrm{g}) \\
(N 197)\end{array}$} & \multicolumn{2}{|c|}{$\begin{array}{l}\mathrm{K}(\mathrm{mg}) \\
(N 197)\end{array}$} & \multicolumn{2}{|c|}{$\begin{array}{l}\text { Energy (kJ) } \\
\quad(N 58)\end{array}$} & \multicolumn{2}{|c|}{$\begin{array}{l}\text { Protein }(\mathrm{g}) \\
(N \text { 155) }\end{array}$} & \multicolumn{2}{|c|}{$\begin{array}{l}\mathrm{K}(\mathrm{mg}) \\
(N \mathrm{155})\end{array}$} & \multicolumn{2}{|c|}{$\begin{array}{l}\text { Energy (kJ) } \\
\quad(N 69)\end{array}$} & \multicolumn{2}{|c|}{$\begin{array}{l}\text { Protein }(\mathrm{g}) \\
(N \text { 193) }\end{array}$} & \multicolumn{2}{|c|}{$\begin{array}{l}\mathrm{K}(\mathrm{mg}) \\
(N 193)\end{array}$} \\
\hline & Estimate & $\mathrm{SD}$ & Estimate & SD & Estimate & SD & Estimate & SD & Estimate & SD & Estimate & SD & Estimate & $\mathrm{SD}$ & Estimate & SD & Estimate & SD \\
\hline \multicolumn{19}{|l|}{ BMI-related determinants } \\
\hline Opinion BW: too high & -544 & 655 & $2 \cdot 79$ & $3 \cdot 30$ & $-41 \cdot 6$ & 157 & $76 \cdot 8$ & 707 & $4 \cdot 23$ & 4.54 & 209 & 181 & 265 & 682 & $9 \cdot 80^{\star}$ & $4 \cdot 37$ & 245 & 187 \\
\hline Dieting: sometimes & -307 & 635 & $-4 \cdot 37$ & $2 \cdot 98$ & -154 & 146 & -812 & 702 & $-6 \cdot 49$ & $4 \cdot 22$ & $1 \cdot 10$ & 177 & -806 & 641 & $-4 \cdot 26$ & $4 \cdot 10$ & -200 & 175 \\
\hline Total dieting attempts & $-31 \cdot 8$ & 29.3 & -0.08 & 0.14 & -0.84 & $6 \cdot 70$ & -49.2 & 41.0 & 0.19 & 0.20 & 1.90 & 7.91 & $-40 \cdot 6$ & $30 \cdot 1$ & -0.04 & 0.19 & -9.52 & 7.97 \\
\hline 5-year weight difference $(\mathrm{kg})$ & 11.4 & 91.7 & $-0.52^{*}$ & 0.26 & $-16 \cdot 4$ & $12 \cdot 2$ & $90 \cdot 2$ & 106 & -0.35 & 0.35 & -10.6 & 13.3 & $-26 \cdot 0$ & $95 \cdot 2$ & -0.47 & 0.35 & $-15 \cdot 9$ & 14.7 \\
\hline Physical activity (MET/d) & -2290 & 1600 & -3.85 & 7.39 & 8.42 & 364 & $-3916^{\star}$ & 1824 & $-22 \cdot 7^{\star}$ & $10 \cdot 7$ & -692 & 422 & $-3799^{\star}$ & 1714 & -11.9 & 9.98 & -254 & 449 \\
\hline Body fat $(\%)$ & -55.8 & $62 \cdot 4$ & 0.29 & 0.28 & 3.50 & $13 \cdot 2$ & $61 \cdot 7$ & 73.4 & 0.53 & 0.41 & $19 \cdot 0$ & $16 \cdot 6$ & $43 \cdot 1$ & 64.9 & $0.91^{*}$ & 0.36 & $43 \cdot 1^{*}$ & $15 \cdot 4$ \\
\hline \multicolumn{19}{|l|}{ Other determinants } \\
\hline Stress level & -93.9 & 99.9 & 0.65 & 0.45 & 15.4 & 21.4 & $16 \cdot 5$ & 108 & 0.45 & 0.58 & -9.92 & 23.4 & -5.98 & 104 & 0.83 & 0.60 & 7.82 & $25 \cdot 5$ \\
\hline Restrained eater & -402 & 401 & $-1 \cdot 23$ & 1.94 & $25 \cdot 8$ & 92.5 & -516 & 440 & -3.45 & $2 \cdot 71$ & $-15 \cdot 3$ & 109 & -372 & 417 & $-3 \cdot 77$ & 2.57 & $-93 \cdot 3$ & 110 \\
\hline Emotional eater & -594 & 450 & -0.42 & 2.06 & -72.5 & 97.9 & 366 & 495 & $4 \cdot 25$ & $2 \cdot 79$ & $30 \cdot 4$ & 113 & 297 & 471 & 3.22 & $2 \cdot 75$ & $37 \cdot 0$ & 118 \\
\hline External eater & 197 & 604 & 2.40 & $2 \cdot 74$ & $-27 \cdot 0$ & 131 & 897 & 649 & 4.20 & 3.73 & 174 & 149 & 596 & 623 & 2.63 & 3.66 & 109 & 156 \\
\hline Knowledge & -5.09 & 142 & -0.15 & 0.80 & -6.50 & 39.2 & 130 & 141 & -0.83 & 1.09 & -7.69 & $45 \cdot 9$ & 102 & 141 & -0.04 & 1.09 & -29.5 & $46 \cdot 6$ \\
\hline Self-identity & -291 & 316 & -1.09 & 1.66 & $45 \cdot 9$ & $78 \cdot 6$ & -528 & 332 & -1.92 & $2 \cdot 16$ & 103 & 86.5 & -318 & 323 & -2.09 & $2 \cdot 24$ & $-11 \cdot 7$ & 94.2 \\
\hline Perceived barriers & 542 & 405 & $-3 \cdot 26$ & 1.98 & -109 & 95.6 & $984^{*}$ & 444 & -0.35 & $2 \cdot 80$ & $61 \cdot 2$ & 116 & 341 & 413 & -1.67 & 2.69 & -78.0 & 115 \\
\hline Smoking: current & 1763 & 1144 & -7.51 & $5 \cdot 10$ & -116 & 254 & 1559 & 1122 & -0.18 & 6.93 & 220 & 275 & -192 & 1163 & $-16 \cdot 7^{\star}$ & $6 \cdot 89$ & $-600^{*}$ & 288 \\
\hline Smoking: former & 183 & 611 & 1.16 & $2 \cdot 74$ & 173 & 135 & -11.9 & 710 & -0.20 & 3.94 & 99.1 & 157 & -428 & 645 & -2.52 & 3.65 & -24.7 & 157 \\
\hline Living with partner & $59 \cdot 4$ & 741 & -3.28 & 3.33 & -215 & 158 & 743 & 873 & 2.49 & 4.56 & -127 & 182 & -285 & \pm 767 & 2.64 & 4.45 & 31.4 & 189 \\
\hline Living with children & $-1495^{\star}$ & 730 & -2.55 & 3.60 & -157 & 168 & -402 & 827 & 1.92 & 5.07 & $-49 \cdot 8$ & 208 & -1269 & 764 & -3.98 & 4.73 & $28 \cdot 2$ & 204 \\
\hline
\end{tabular}

BW, body weight; MET, MET, metabolic equivalents of task; PABA, $p$-aminobenzoic acid.

Determinants were entered in a multivariate linear regression model in addition to the basic determinants (BMI, gender, age and education level) and PABA completeness, one at a time.

${ }^{*}$ Significant at $P \leq 0.05$. 
misreporting of energy also were found for body fatness, body image (which is related to one's opinion about one's body weight) and weight differences ${ }^{(18)}$. Percentage body fat is different for women and men. In our study women had a mean body fat percentage of $34 \%$ and men of $22 \%$. However, in none of the models was the interaction term for body fat and gender significant, thus the effect of body fat would not be different for men and women. For the measurement of body fat, subject preparation was not standardized in our study. We do not expect that this had a relevant impact on the percentage body fat measured ${ }^{(48)}$. Other studies also found an association between smoking status and misreporting of energy intake $e^{(7,14)}$, that we did not observe. To our knowledge no other studies found associations between misreporting and perception of barriers or living with children. Direct comparison of these findings with our results is difficult as in these studies only misreporting of energy intake was investigated, and it should be taken into account that not all of these studies used DLW to assess the level of misreporting. Furthermore, due to the high costs of DLW, the sample size for energy was small in our study. Also, physical activity level was measured in different ways (e.g. with accelerometers (as in our study) or questionnaires) and the populations are different in the different studies.

It is also worthwhile to discuss the determinants that did not show a significant association with misreporting, such as education, knowledge and restrained eating. For the first two variables, the reason for not observing an association may be the limited variation in our study population. Over $50 \%$ of our study population was highly educated and only 19\% was classified as low educated. Next, under-reporters could be expected to have a higher knowledge on healthy foods and thus (selectively) not have reported unhealthy foods. Our knowledge questionnaire might not have had a high discriminatory power (the average score was 15 out of 17) for our participants, as they were highly motivated (they were willing to fill in multiple questionnaires, collect two DP, fill in two FFQ, administer multiple $24 \mathrm{hR}$ and seventy participants joined the DLW study) and could therefore also be expected to have a good knowledge about healthy eating. Although we did not observe an association between restrained eating and misreporting, restrained eating has been associated with misreporting of energy intake ${ }^{(49,50)}$. However, there are restrained eaters who report adequately and non-restrained eaters who report poorly ${ }^{(6,7,16)}$; thus final conclusions cannot be drawn.

We estimated the bias by taking the intake of one day minus the average intake of two days estimated by the biomarkers. The assessment days were included separately in the regression model because we wanted to estimate the day-to-day variance of the intake as assessed by DP, $24 \mathrm{hR}$ or FFQ. As the reference method, we used the average of two days of intake estimated by the biomarkers instead of one day to better reflect the usual intake, as we did previously ${ }^{(1)}$.
Misreporting of dietary intake is often associated with weight status and for specific foods and food groups, thus true associations between diet and diseases may be distorted by this bias ${ }^{(51)}$. Various methods have been proposed to adjust energy intake for misreporting and most of these methods are based on the exclusion of the group of implausible energy reporters ${ }^{(52-54)}$. This might cause selection bias ${ }^{(55)}$, as the people identified as being implausible reporters of energy intake might also be the group with specific characteristics, e.g. a higher BMI, than the plausible reporters. Thus (statistical) methods correcting the individuals misreporting would be preferred.

The DP, on the one hand, and the $24 \mathrm{hR}$ and FFQ, on the other, are conceptually different dietary assessment methods. The DP is not based on memory, portion sizes do not need to be estimated, and data from food composition databases are not needed to assess the nutrient content of the $\mathrm{DP}$, whereas this is the case for both FFQ and $24 \mathrm{hR}$. Therefore, it may be expected that the error sources among these methods are different. This could explain why age and BMI for under-reporting of $\mathrm{K}$ and physical activity for under-reporting of energy are more important determinants for the 24hR and FFQ than for the DP. On the other hand, 5-year weight difference for under-reporting of protein and living with children for under-reporting of energy were more important determinants for the DP than for the $24 \mathrm{hR}$ and FFQ. Further research is necessary in order to explain these findings.

We investigated the association between determinants and misreporting. Identifying determinants associated with misreporting helps our understanding of what processes are ongoing during dietary reporting. Eventually, such information should be used to improve the assessment of dietary intake. An attempt has been made, for example, to develop a dietary assessment instrument for use in obese individuals; however, after several validation studies in different obese target groups, it did not prove to consistently show valid results ${ }^{(43)}$.

Furthermore, information on determinants of misreporting should be collected in nutritional epidemiological studies and inclusion in calibration models could improve the calibration model. However, deciding which covariables to include in a calibration model is complex; especially BMI is difficult, because of its multiple possible roles ${ }^{(56,57)}$. For example, in epidemiological research BMI could be a predictor of intake but also the health outcome. Further research is needed on how best to choose the covariates in a calibration model without introducing other sources of bias.

\section{Conclusion}

We conclude that in this Dutch study population, only BMI was consistently associated with under-reporting of energy and nutrients by the different dietary assessment methods. Thus BMI should always be taken into account when assessing and correcting dietary intake. 


\section{Acknowledgements}

Acknowledgements: The authors thank Anne van de Wiel, MSc, for making it possible to use data from the NQplus study. The authors thank Mira Mutiyani, BSc, Sanne Marije Seves, BSc, and Cecilia Ferreira Lima, BSc, for their help in analysing the DP samples and Corine Perenboom for her help in preparing the $24 \mathrm{hR}$ data. In addition, the authors thank the individuals from the DuPLO study for participating in the present study. Financial support: The NQplus study was funded by ZonMw (grant number 91110030) and Wageningen University. The DuPLO study was funded by VLAG (Voeding, Levensmiddelentechnologie, Agrobiotechnologie en Gezondheid), a graduate school of Wageningen University. ZonMW and VLAG had no role in the design, analysis or writing of this article. Conflict of interest: None. Authorship: L.T. collected the data, contributed to the study design, data analysis and interpretation of findings, and wrote the manuscript. A.G., P.v.V. and J.H.M.d.V. contributed to the study design and interpretation of findings and revised the earlier versions of the manuscript. H.C.B. contributed to the data analysis and interpretation of findings and revised the earlier versions of the manuscript. P.J.M.H., P.C.H.H. and E.J.M.F. contributed to the study design and revised the earlier versions of the manuscript. All authors read and approved the final version of the manuscript. Ethics of buman subject participation: This study was conducted according to the guidelines laid down in the Declaration of Helsinki and all procedures involving human subjects were approved by the medical ethical committee of Wageningen University. Written informed consent was obtained from all participants.

\section{References}

1. Crispim SP, Geelen A, De Vries JHM et al. (2012) Bias in protein and potassium intake collected with 24-h recalls (EPIC-Soft) is rather comparable across European populations. Eur J Nutr 51, 997-1010.

2. Freedman LS, Commins JM, Moler JE et al. (2014) Pooled results from 5 validation studies of dietary self-report instruments using recovery biomarkers for energy and protein intake. Am J Epidemiol 180, 172-188.

3. Trabulsi J \& Schoeller DA (2001) Evaluation of dietary assessment instruments against doubly labeled water, a biomarker of habitual energy intake. Am J Physiol Endocrinol Metab 281, E891-E899.

4. Isaksson B (1993) A critical evaluation of the duplicate-portion technique in dietary surveys. Eur J Clin Nutr $\mathbf{4 7}, 457-460$.

5. Stockley L (1985) Changes in habitual food intake during weighed inventory surveys and duplication diet collections. A short review. Ecol Food Nutr 17, 263-269.

6. Maurer J, Taren DL, Teixeira PJ et al. (2006) The psychosocial and behavioral characteristics related to energy misreporting. Nutr Rev 64, 53-66.

7. Livingstone MB \& Black AE (2003) Markers of the validity of reported energy intake. J Nutr 133, Suppl. 3, 895S-920S.

8. Willett W (2013) Nutritional Epidemiology, 3rd ed. Oxford: Oxford University Press.
9. Jenab M, Slimani N, Bictash M et al. (2009) Biomarkers in nutritional epidemiology: applications, needs and new horizons. Hum Genet 125, 507-525.

10. Freisling H, Van Bakel MME, Biessy C et al. (2012) Dietary reporting errors on $24 \mathrm{~h}$ recalls and dietary questionnaires are associated with BMI across six European countries as evaluated with recovery biomarkers for protein and potassium intake. Br J Nutr 107, 910-920.

11. Mossavar-Rahmani Y, Shaw PA, Wong WW et al. (2015) Applying recovery biomarkers to calibrate self-report measures of energy and protein in the Hispanic Community Health Study/ Study of Latinos. Am J Epidemiol 181, 996-1007.

12. Mossavar-Rahmani Y, Tinker LF, Huang Y et al. (2013) Factors relating to eating style, social desirability, body image and eating meals at home increase the precision of calibration equations correcting self-report measures of diet using recovery biomarkers: findings from the Women's Health Initiative. Nutr J 12, 63.

13. Freedman LS, Commins JM, Moler JE et al. (2015) Pooled results from 5 validation studies of dietary self-report instruments using recovery biomarkers for potassium and sodium intake. Am J Epidemiol 181, 473-487.

14. Briefel RR, Sempos CT, McDowell MA et al. (1997) Dietary methods research in the third National Health and Nutrition Examination Survey: underreporting of energy intake. $A m \mathrm{~J}$ Clin Nutr 65, 4 Suppl., 1203S-1209S.

15. Voss S, Kroke A, Klipstein-Grobusch K et al. (1998) Is macronutrient composition of dietary intake data affected by underreporting? Results from the EPIC-Potsdam study. Eur J Clin Nutr 52, 119-126.

16. Tooze JA, Subar AF, Thompson FE et al. (2004) Psychosocial predictors of energy underreporting in a large doubly labeled water study. Am J Clin Nutr 79, 795-804.

17. Price GM, Paul AA, Cole TJ et al. (1997) Characteristics of the low-energy reporters in a longitudinal national dietary survey. Br J Nutr 77, 833-851.

18. Novotny JA, Rumpler WV, Riddick H et al. (2003) Personality characteristics as predictors of underreporting of energy intake on 24-hour dietary recall interviews. J Am Diet Assoc 103, 1146-1151.

19. Bedard D, Shatenstein B \& Nadon S (2004) Underreporting of energy intake from a self-administered food-frequency questionnaire completed by adults in Montreal. Public Health Nutr 7, 675-681.

20. Johnson RK, Soultanakis RP \& Matthews DE (1998) Literacy and body fatness are associated with underreporting of energy intake in US low-income women using the multiplepass 24-hour recall: a doubly labeled water study. J Am Diet Assoc 98, 1136-1140.

21. Trijsburg L, de Vries JH, Boshuizen HC et al. (2015) Comparison of duplicate portion and $24 \mathrm{~h}$ recall as reference methods for validating a FFQ using urinary markers as the estimate of true intake. Br J Nutr 114, 1304-1312.

22. Conway JM, Ingwersen LA, Vinyard BT et al. (2003) Effectiveness of the US Department of Agriculture 5-step multiple-pass method in assessing food intake in obese and nonobese women. Am J Clin Nutr 77, 1171-1178.

23. Siebelink E, Geelen A \& De Vries JHM (2011) Self-reported energy intake by FFQ compared with actual energy intake to maintain body weight in 516 adults. Br J Nutr 106, 274-281.

24. Streppel MT, De Vries JH, Meijboom S et al. (2013) Relative validity of the food frequency questionnaire used to assess dietary intake in the Leiden Longevity Study. Nutr J 12, 75.

25. Nevo (2011) Dutch Food Composition Database. The Hague: Stichting Nevo.

26. Hambleton LG \& Noel RJ (1975) Protein analysis of feeds, using a block digestion. J Assoc Off Anal Chem 58, 143-145.

27. Jones DB (1941) Factors for Converting Percentages of Nitrogen in Foods and Feeds into Percentages of Proteins. Washington, DC: US Department of Agriculture. 
28. Bingham SA \& Cummings JH (1985) Urine nitrogen as an independent validatory measure of dietary intake: a study of nitrogen balance in individuals consuming their normal diet. Am J Clin Nutr 42, 1276-1289.

29. Jakobsen J, Ovesen L, Fagt S et al. (1997) Para-aminobenzoic acid used as a marker for completeness of 24 hour urine: assessment of control limits for a specific HPLC method. Eur J Clin Nutr 51, 514-519.

30. Horwitz W (1975) Official Methods of Analysis of the Association of Official Analytical Chemists. Washington, DC: Association of Official Analytical Chemists.

31. Osborne D \& Voogt P (1978) The Analysis of Nutrients in Foods. London: Academic Press.

32. Klee MS \& Meng CK (1998) Ambient Headspace Analysis with the Agilent 7683 Automatic Liquid Sampler Agilent Technologies. Application Note. Wilmington, DE: Agilent Technologies, Inc.

33. Food and Agriculture Organization of the United Nations (2003) Food Energy - Methods of Analysis and Conversion Factors. Rome: FAO.

34. Siebelink E, de Vries JHM, Trijsburg L et al. (2015) Evaluation of calculated energy and macronutrient contents of diets provided in controlled dietary intervention trials by chemical analysis of duplicate portions. J Food Compost Anal 43, 68-74.

35. International Atomic Energy Agency (2009) Assessment of Body Composition and Total Energy Expenditure in Humans Using Stable Isotope Techniques. IAEA Human Health Series no 3. Vienna: IAEA.

36. Weir JBD (1949) New methods for calculating metabolic rate with special reference to protein metabolism. J Physiol 109, 1-9.

37. Trijsburg L (2016) Measurement errors in dietary assessment using duplicate portions as reference method. PhD Thesis, Wageningen University.

38. Swartz AM, Strath SJ, Bassett DR Jr et al. (2000) Estimation of energy expenditure using CSA accelerometers at hip and wrist sites. Med Sci Sports Exerc 32, 9 Suppl., S450-S456.

39. Cohen S, Kamarck T \& Mermelstein R (1983) A global measure of perceived stress. J Health Soc Behav 24, 385-396.

40. Van Strien T, Frijters JER, Bergers GPA et al. (1986) The Dutch Eating Behavior Questionnaire (DEBQ) for assessment of restrained, emotional, and external eating behavior. Int J Eating Disord 5, 295-315.

41. Wardle J (1987) Eating style: a validation study of the Dutch Eating Behaviour Questionnaire in normal subjects and women with eating disorders. J Psychosom Res 31, 161-169.

42. Hooft van Huysduynen EJC (2014) Towards healthy diets for parents: effectiveness of a counselling intervention. PhD Thesis, Wageningen University.

43. Lissner L (2002) Measuring food intake in studies of obesity. Public Health Nutr 5, 889-892.
44. Subar AF, Kipnis V, Troiano RP et al. (2003) Using intake biomarkers to evaluate the extent of dietary misreporting in a large sample of adults: the OPEN study. Am J Epidemiol 158, $1-13$

45. Taren DL, Tobar M, Hill A et al. (1999) The association of energy intake bias with psychological scores of women. Eur J Clin Nutr 53, 570-578.

46. Donders-Engelen M \& van der Heijden L (2003) Maten, gewichten en codenummers 2003. Wageningen: Wageningen UR, Vakgroep Humane Voeding.

47. van Rossum CTM, Fransen HP, Verkaik-Kloosterman J et al. (2011) Dutch National Food Consumption Survey 2007-2010: Diet of Children and Adults aged 7 to 69 years. Bilthoven: National Institute of Public Health.

48. Horber FF, Thomi F, Casez JP et al. (1992) Impact of hydration status on body composition as measured by dual energy X-ray absorptiometry in normal volunteers and patients on haemodialysis. Br J Radiol 65, 895-900.

49. Asbeck I, Mast M, Bierwag A et al. (2002) Severe underreporting of energy intake in normal weight subjects: use of an appropriate standard and relation to restrained eating. Public Health Nutr 5, 683-690.

50. Bathalon GP, Tucker KL, Hays NP et al. (2000) Psychological measures of eating behavior and the accuracy of 3 common dietary assessment methods in healthy postmenopausal women. Am J Clin Nutr 71, 739-745.

51. Mendez MA (2015) Invited commentary: Dietary misreporting as a potential source of bias in diet-disease associations: future directions in nutritional epidemiology research. Am J Epidemiol 181, 234-236.

52. Mendez MA, Popkin BM, Buckland G et al. (2011) Alternative methods of accounting for underreporting and overreporting when measuring dietary intake-obesity relations. Am J Epidemiol 173, 448-458.

53. Rhee JJ, Sampson L, Cho E et al. (2015) Comparison of methods to account for implausible reporting of energy intake in epidemiologic studies. Am J Epidemiol 181, 225-233

54. Black AE, Prentice AM, Goldberg GR et al. (1993) Measurements of total energy expenditure provide insights into the validity of dietary measurements of energy intake. J Am Diet Assoc 93, 572-579.

55. Hernán MA, Hernández-Díaz S \& Robins JM (2004) A structural approach to selection bias. Epidemiology 15, 615-625.

56. Prentice RL \& Huang Y (2011) Measurement error modeling and nutritional epidemiology association analyses. Can J Stat 39, 498-509.

57. Zheng C, Beresford SA, Van Horn L et al. (2014) Simultaneous association of total energy consumption and activity-related energy expenditure with risks of cardiovascular disease, cancer, and diabetes among postmenopausal women. Am J Epidemiol 180, $526-535$. 